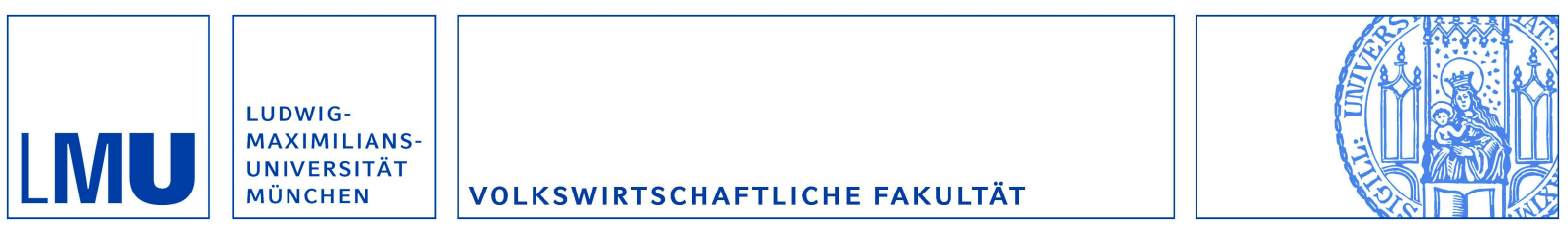

Kocher, Martin G.:

How trust in social dilemmas evolves with age

Munich Discussion Paper No. 2015-13

Department of Economics

University of Munich

Volkswirtschaftliche Fakultät

Ludwig-Maximilians-Universität München

Online at https://doi.org/10.5282/ubm/epub.25159 


\title{
How trust in social dilemmas evolves with age*
}

\author{
Martin G. Kocher \\ University of Munich, Germany \\ University of Gothenburg, Sweden \\ Queensland University of Technology, Brisbane, Australia \\ CESifo, Munich, Germany
}

\section{To appear as a chapter in: \\ Van Lange, P. A. M., Rockenbach, B., \& Yamagishi, T. (in press, eds.). Social dilemmas: New perspectives on trust. New York: Oxford University Press.}

\begin{abstract}
While trust and trustworthiness provide a fundamental foundation for human relationships, little is known about how trusting and trustworthy behavior in social dilemmas is related to age and aging. A few papers use data from surveys such as the World Values Survey to address a potential connection between trust and age. In this chapter, we will mainly focus on trusting and trustworthy behavior elicited with the use of the seminal trust game (Berg et al., 1995) and with games implementing a similar incentivized interaction structure. The results suggest that trust and trustworthiness increase with young age until adolescence. Trustworthiness reaches the level of adults at an earlier age (at around 15-16 years of age) than trusting behavior (around adulthood). Survey results differ from incentivized experiments when it comes to a potential development of trust in adulthood. The former indicate a steady rise in trust levels at a small rate when becoming older, whereas the latter show a decline, starting at an age of about 60 years.
\end{abstract}

JEL Code: C72; C91.

Keywords: Trust, trustworthiness, age.

* I am indebted to Lisa Spantig and Paul van Lange for very helpful comments and suggestions. 


\section{Introduction}

While the importance of trust and trustworthiness in human interaction has been stressed repeatedly in the scholarly literature in the social sciences and in biology, there is still surprisingly little understanding of some of the determinants of trust. How is trust related to experience of trustworthiness? How can trust be repaired after an incidence of breaching trust? To what extent does trust depend on observable characteristics or stereotypes?

In the following, we focus on an aspect of trust that has long been neglected by economists: the relationship between trusting as well as trustworthy behavior in social dilemmas and age. ${ }^{1}$ As an observable characteristic, the impact of age on trust and trustworthiness has many real-world implications. For instance, understanding age as a potential determinant of trust among children and adolescents might help develop school curricula and learning environments for children that are conducive to establishing trusting and cooperative relationships among themselves. Comparing trust and trustworthiness of parents and their children in different family situations could be useful in disentangling different intergenerational transmission mechanisms of trust and cooperation. Looking at trust between generations and at a possible drop in trust at old age should provide insights into potential problems associated with an aging society. And finally, understanding the evolution of trust and trustworthiness could be helpful in providing indications on how to repair trust after incidences of trust loss.

Trust and trustworthiness are key determinants of economic success measured both at the micro-level and at the macro-level. Almost any economic transaction at the micro-level requires trust, trustworthiness and cooperation. Since contracts can never specify all contingencies of an economic exchange - no matter how detailed they are - there is always a required minimum level of trust and trustworthiness to make economic interactions happen, and very often the required level is quite profound, also in high-stakes environments. At the macro-level, aggregate trust in a region or a country have shown to be positively correlated with economic outcomes such as GDP (LaPorta et al., 1997), growth (Knack and Keefer, 1997; Zak and Knack, 2001), inflation rates (LaPorta et al., 1997), or, for instance, the volume of trade between countries (Guiso et al., 2009).

There are several definitions of trust, but recent research in economics usually refers to Coleman (1990), whose characterization of trust is often slightly adapted and relates to a two-person interaction. In the following, we see trust as the voluntary placement of resources or decision making power in the hands of another party (the trustee) without legal commitment or informal retaliatory options (such as punishment) by a trustor (or investor). To make the setup interesting, trust must potentially bear the expectation to be better off by trusting than by not trusting if the trustee is trustworthy. In other words, the interaction between the trustor and the trustee entails a potential efficiency gain that leaves the trustor better off if the trustee is trustworthy and worse off if not. Trust

\footnotetext{
${ }^{1}$ For an early literature overview in psychology see Bernath and Feshbach (1995).
} 
thus means that the trustor makes him- or herself vulnerable to the decisions of the trustee (Rousseau et al., 1998). Given the richness of the definition, it is difficult to directly link trusting and trustworthy behavior to underlying (economic) preferences and beliefs (expectations).

Trust is obviously related to cooperation in social dilemmas (see Gächter et al., 2004), since cooperation often requires trust in the cooperation of others. Social dilemmas are a more general class of situations. They characterize (potentially multi-person) interactions that entail a trade-off between individual rationality and collective rationality. If everyone cooperates or trusts, everyone is better off than otherwise. However, there is the temptation to unilaterally deviate from trusting or cooperating, which leads to an exploitation of others and an even higher payoff for the deviating individual. If everybody deviates, everybody is worse off.

Trust, trustworthiness and cooperative inclinations have been measured in many ways in experimental studies and in empirical studies based on field data. The experimental literature started with the famous prisoner's dilemma game (Poundstone, 1992), followed by different versions of the public goods game (Ledyard, 1995). Some decades later the gift-exchange game (Fehr et al., 1993) and, in particular, the trust (or investment) game (Berg et al., 1995) provided experimental workhorses that allowed studying trust and trustworthiness more directly. Concurrently, large-scale international surveys and panels enabled economists and other social scientists to conduct studies on trust and trustworthiness for international comparisons.

The rest of the paper is organized as follows: Section 2 starts with a discussion of common methodological challenges when assessing the relationship between trust as well as trustworthiness and age. In section 3 of this chapter, we discuss the main empirical findings of non-incentivized survey measures of trust and trustworthiness that take age as a determinant of trust into account. Section 4 looks at survey panels and online studies using partly incentivized methods to study the evolution of trust and trustworthiness with age, and in section 5, we survey the experimental literature, mainly focusing on the seminal trust game, including small variations that have been applied in the laboratory or in the field. Section 6 discusses potential underlying mechanisms that could explain developments of trust and trustworthiness with age. Section 7 concludes the paper and lists remaining open puzzles, blind spots in the literature, and avenues for future research.

\section{Common challenges when studying trust and age}

Eliciting trust and trustworthiness seems straightforward to most researches in the social sciences. The bulk of the literature nowadays uses either a variant of the World Values Survey or a variant of the trust game (Berg et al., 1995). In the following, the two methods are introduced very briefly and common methodological challenges when studying trust and trustworthiness in combination with age as an independent variable are discussed. 


\subsection{Two often applied methods to elicit trust and trustworthiness}

The World Values Survey (WVS) ${ }^{2}$ contains two types of non-incentivized questions related to trust, a binary one and a set of ones on a four-point scale. The binary question used for more than 30 years reads "Generally speaking, would you say that most people can be trusted or that you need to be very careful in dealing with people?", with answers "Most people can be trusted" and "Need to be very careful". The questions on the four-point scale are asked in relationship to specific groups: "I'd like to ask you how much you trust people from various groups. Could you tell me for each whether you trust people from this group completely, somewhat, not very much or not at all? Your family [Your neighborhood; People you know personally; People you meet for the first time; People of another religion; People of another nationality]." The answers are rated on the following categories: "Trust completely", Trust somewhat", "Do not trust very much", and "Do not trust at all". These questions exist for three waves of the survey. More questions have been added (e.g., "Now could you tell me whether you agree strongly, agree a little, neither agree nor disagree, disagree a little or disagree strongly with each of the following statements?: I see myself as someone who is generally trusting.”), but they are not consistently used in the waves or exist only since recently. Researchers have used the answers to these and similar questions related to trust and trustworthiness extensively in scientific studies. Interestingly, cooperation in social dilemmas as a general concept has not been researched much based on survey questions, probably because it is more complicated to explain the incentives in a social dilemma within one survey question, and "cooperation" is more difficult to discuss in the abstract, without a specific situation in mind.

When it comes to incentivized elicitation methods of trust and trustworthiness, the trust game introduced by Berg et al. (1995) is the most commonly used paradigm nowadays. It is a two-player, two-stage bargaining game, and it is usually incentivized monetarily. Both the trustor and the trustee have the same initial endowment $X>0$. The trustor can send a positive amount $x \leq X$ to the trustee. The trustee receives $n^{*} \mathrm{x}$ (with $\mathrm{n}=3$, usually) and can return any amount $\mathrm{y}$, with $0 \leq \mathrm{y} \leq \mathrm{nx}$. The final payoff for the trustor is $X-x+y$, and for the trustee it is $X+n x-y$. The decision of the trustor is interpreted as a measure of trust, whereas the decision of the trustee (dependent on the trust level) is interpreted as a measure of trustworthiness or reciprocity. Indeed, as will be discussed in greater detail in section 6 , there might be many underlying motives or preferences that would explain the behavior of the two decision makers without alluding to trust and trustworthiness. Examples are efficiency preferences, specific forms of inequality aversion, or altruism.

In the following, we will discuss a set of methodological challenges when measuring trust and trustworthiness across different age groups. Most of these challenges apply to both non-incentivized survey measures and incentivized experiments based on interaction. One important aspect to note in general is that age is, obviously, never an exogenous variable. Even in experiments it is impossible to

\footnotetext{
${ }^{2}$ http://www.worldvaluessurvey.org
} 
assign age randomly to experimental participants (although age perception can be influenced by the use of experimental methods to a certain extent (Bargh et al., 1996; Doyen et al., 2012 (failed replication))). Hence, there is no direct causal inference, and differences in behavior across different age groups could potentially stem from other variables that have been omitted or that have not been properly controlled for (for instance, differences in cognitive abilities). As a consequence, methodological aspects and the details of the elicitation procedure become even more important when studying age differences in trust and trustworthiness than they are when assessing concepts that can be exogenously varied.

\subsection{Sample selection issues}

Sample selection is a particular concern in studies that compare behavior of different groups. Imagine that one wants to study levels of trust and trustworthiness of children, adolescents, and adults; i.e. one aims to characterize trust and trustworthiness over the whole life span, only excluding very young children. Apart from representative samples that are very expensive, it is difficult to balance the sample across different age groups. The problem is particularly severe with younger children, for who sample selection criteria have to be partly based on their parents' or household characteristics. If one conducts experiments in kindergartens and schools, which is often the method of choice for practical reasons, it is obviously important that different kindergarten and school types are comparable and that there is no systematic selection of certain students into certain institutions, for instance, with regard to gender (which, however, can be controlled for) or with regard to the propensity of attending specific school types or pursuing specific educational careers later on. If sample selection is not properly controlled for, age differences in the levels of trust and trustworthiness cannot be ascribed to the variable age; they could also be a consequence of the sample selection.

\subsection{Procedures of elicitation}

One of the most daunting tasks for the researcher is the choice of proper stimuli and appropriate questions. Obviously, an average eight-year old kid has a different level of comprehension and cognitive ability than an adult experimental participant. In a survey-based elicitation, the questions to be asked would potentially have to be age-adjusted, creating possible confounds of age and a change in the elicitation method.

Using incentivized experiments also requires comparable stimuli across different age groups. The description of the trust game has to be as similar as possible across different age groups, without sounding weird or ill-adapted for specific groups. For instance, a description of the trust game suitable for a six-year-old kid might sound very odd to an 18-year old student. A compromise between the two objectives is sometimes difficult. One potential workaround, at least to a certain extent, is the use of comprehension questions after the experimental instructions, but before the start of the experiment that give an impression of the level of understanding of the experimental instructions by different age 
groups and that allow the potential exclusion of participants from the analysis based on comprehension. Again, sample selection could become an issue if the number of excluded observations is larger in certain age groups than in others.

\subsection{Comparability of incentives and reward media}

While non-incentivized questionnaires usually only care for the incentives to participate and to take the survey seriously, incentivized experiments have to be more careful when it comes to the question of how to use incentives and how to make them comparable across different groups. ${ }^{3}$ Even though, surprisingly, there is not much hard evidence from the laboratory on differences in behavior in simple games that are fully incentivized and those that are not, most economists think that it is important to incentivize the trust game and not to use it as a hypothetical scenario in order to reduce the influence of social desirability. Potentially, the choice of incentives versus no incentives has differential effects on different age levels, but again, we are not aware of systematic empirical evidence on this question.

The first choice to be taken is the choice of reward medium. For various reasons monetary incentives is the best available choice. There are no serious issues of valuation and comparability. Even young children have a clear understanding of money as a concept and are able to assess monetary amounts, starting at an age of around seven years. For younger children, it is obviously necessary to use alternative reward media, and the best choice here is to use tokens that can be exchanged for a choice out of a set of about equally-valued small toys. The more tokens one possesses after the interaction, the more toys can be chosen. This basically creates a currency in its own right that is easy to understand for younger kids and can be used starting at an age of about four years, as long as absolute numbers involved in the "currency" exchange remain small.

Comparability of stakes across different age groups is supposedly the most difficult problem. Some studies use average weekly allowances of children from their parents as a proxy for different levels of purchasing power, but allowances are usually very hard to compare because they include different required expenses for different age groups in childhood (e.g., older kids might be asked to buy lunches from their allowances, whereas younger kids are not). Comparability with wages or income of adults is even harder to achieve.

Interestingly, the exact stake size above a certain minimum does not seem to play an important role in many interactions. While some studies report stake size effects in simple games, usually they are small and do not affect decisions profoundly (see, for instance, Camerer, 2003; Kocher et al., 2008; Fehr et al., 2014). However, most of the empirical results on stake size effects are based on a comparison between standard experimental stakes and higher stakes. There is much less evidence for potential differences in behavior between low stakes versus standard stakes, because experiments in

\footnotetext{
${ }^{3}$ An obvious example in the literature for the relevance of comparability of incentives is the comparison of trust and trustworthiness in students and CEOs (Fehr and List, 2004).
} 
the economics literature usually provide incentives that are at least as high as the opportunity costs of experimental participants.

In Sutter and Kocher (2007), we look at different stake levels for students to be able to exclude that differences in trust and trustworthiness between younger kids and students are driven by stake size effects, using also comparatively very small stakes for students in some of the experimental sessions. The results suggest that small stakes go a long way, since we do not observe any significant stake size effects, i.e. we do not observe different choices for different stake levels.

\subsection{Cross section versus time series}

Ideally, one would like to measure the inclination to trust or to be trustworthy at a certain (young) age level, follow the development of these measures over time at the individual level, and link the measures to real-world decision making or real-world outcomes that require trust and trustworthiness. To the best of our knowledge, there is no experimental study of trust and trustworthiness that uses a longitudinal dimension of significant duration. How strongly desirable such a large-scale longitudinal study seems to be from a scientific perspective, it requires an enormous effort by researchers with delayed gratification by potential publications. Furthermore, it involves repeated measurement, creating confounding effects of learning or repeated measurement in its own right (e.g., a preference for consistency could suppress certain developments), which makes inference more difficult. If trust and trustworthiness are indeed influenced by individual experience, then it is almost impossible to control for all possible confounding effects.

In practice, the "development" or "evolution" of trust and trustworthiness with age is usually measured using a cross-section of participants of different age levels. While it is very likely that potential differences between the different age groups are driven by age, it is impossible to rule out cultural change or other cohort effects as the source of the differences. One has to bear this interpretation in mind, in particular, when a study covers a very wide set of different age groups.

Finally, it seems relevant to emphasize that much of the interesting developments in trust and trustworthiness indeed seems to happen at a young age. Thus, it is of importance to care about confounds and methodological challenges, because they are potentially most relevant in comparison between young and old participants and between differently aged kids. Reliable comparisons between differently aged adults are, in general, much easier to achieve.

\section{Trust and age in survey measures}

Despite very large numbers of observations, results on trust and age that are based on non-incentivized survey measures are not fully conclusive. Li and Fung (2013) use data from the 2005 WVS from 38 countries and report a positive relationship between trust and age in adulthood. Fehr (2009) 
summarizes some evidence for a U-shaped relationship, and Fehr et al. (2003) as well as Naef et al. (2008) show a decrease of trust in older age groups for the survey parts of their studies.

More recently, Poulin and Haase (2015) have looked at around 250,000 responses to the binary trust question in the WVS for five waves and 97 societies. At age 20, 23\% of the respondents agree that "most people can be trusted". This rate rises to $35 \%$ for 80 -year olds. They also analyze data from the General Social Survey Panel in the United States. Based on a sample of more than 1,000 participants age is again a positive predictor of trust. Interestingly, the authors report a significant increase not only across cohorts, but also in terms of the longitudinal dimension. The increase over a four-year horizon is uniform across different age groups, but it is small in absolute terms.

Obviously, large-scale survey studies of trust and trustworthiness do unfortunately not include children and adolescents as respondents.

\section{Trust and age measured with large-scale survey panels or online}

The beauty of representative survey panels is that they avoid sample selection biases. If they incorporate incentivized experiments, they combine the advantage of representativeness with the advantage of saliently incentivized experiments. However, they usually do not include non-adult participants, i.e. the age span covered is usually confined to adulthood.

Fehr et al. (2003) and Naef et al. (2008) have included a variant of the original trust game into a representative survey of German households in the so-called German Socio-Economic Panel (GSOEP). In particular, they double the transfer $x$ and also the back transfer from the trustee to the trustor. The latter is unusual, but it does not change the basic nature of the game. Thus, the final payoff for the trustor is $\mathrm{X}-\mathrm{x}+2 \mathrm{y}$, and for the trustee it is $\mathrm{X}+2 \mathrm{x}-\mathrm{y}$. When looking at the relationship between age and trust as well as trustworthiness, they find that older respondents (in particular those over 65) exhibit lower levels of trust by choosing lower transfers $x$ than respondents in their thirties and forties.

A somewhat similar finding is provided by Bellemare and Kröger (2007) based on a representative panel of Dutch households and a standard version of the trust game that is also incentivized. They find that the propensity to trust reaches its maximum at 37 years of age, following an inverted-U-shape with age (see further, Putnam, 2000; Alesina and La Ferrara, 2002). Interestingly, the results in Bellemare and Kröger (2007) seem to suggest that the degree of trustworthiness (i.e. returns y) increases with age, or it follows a U-shaped pattern with age, depending on the particular incentives given. Such a divergence between trust and trustworthiness is difficult to reconcile with rational beliefs, but similar results are provided by incentivized experiments in laboratory settings (see section 5). 
Ermisch et al. (2009) use British household members dropping out from the British Household Panel Study as their participants. They apply a binary trust game and find, in contrast, to the two studies mentioned above an increase in trust with age. However, the sample is comparatively small, and it unclear to what extent all relevant age groups are well-represented in their data.

In general, the magnitudes of the age effects found in the studies mentioned above are not very large, however significant at conventional levels. One reason for this could be the fact that there is no (age) information on the interaction partner. Hence, trustors and trustees do not only play against anonymous interaction partners, but also against interaction partners whose general characteristics they do not know. Relaxing this uncertainty could have an effect, as some of the papers that are discussed in the next section seem to imply.

While more and more experiments are nowadays conducted over the internet and not in the laboratory or in similar environments outside of the laboratory anymore, we are not aware of any incentivized studies that report on the relationship between trust as well as trustworthiness and age over the internet, using Amazon Mechanical Turk, similar web-interfaces or self-developed webinterfaces. Amir et al. (2012) implement a trust game on M-turk with almost 800 participants, but they look at salience effects of different incentives and do not mention age effects in their paper.

\section{Trust and age measured in incentivized laboratory or lab-in-the-field experiments}

The set of laboratory and lab-in-the-field experiments that assess the relationship between trust as well as trustworthiness and age, covering a substantial part of the life span, is comparatively small (a comparison of existing experiments is provided in Table 1). ${ }^{4}$ To the best of our knowledge, Harbaugh et al. (2003b) is the first paper that addresses the issue by comparing levels of trust and trustworthiness among children and adolescents with an age range of eight to 17 years and including an adult participant group. While they do not find any significant correlation between age and trust or trustworthiness, it is possible that their null result is driven by a specific design choice: the use of the strategy vector method. This method asks decision makers to indicate decisions for different contingencies. More specifically, trustors had to make decisions for five different trustees, each from a different age group out of the set 8-year olds, 11-year olds, 14-year olds, 17-year olds and adult, and trustees were asked to indicate returns for each of the possible transfer levels. Unfortunately, no study exists that assesses the effects of the strategy vector method compared to the direct response method for children, but it is conceivable that any potential bias of the strategy vector method (either an

\footnotetext{
${ }^{4}$ Unfortunately, Johnson and Mislin (2011), who provide a meta-study of trust game results, do not look at age as a determinant of trust, but the reason for the omission seems to be the small number of studies reporting age as an independent variable.
} 
experimenter demand effect or possible confusion mitigating treatment effects) is stronger with children than with adult participants.

Sutter and Kocher (2007) apply the direct response method and cover an even larger age span from 8-year olds to a group of retired participants. However, they focus on the interactions between trustors and trustees on the same age level, including common knowledge of this. In other words, 8year old trustors know that they interact with an anonymous 8-year old trustee; 12-year old trustors know that they interact with an anonymous 12-year old trustee; and so on. The results in Sutter and Kocher (2007), based on a slightly modified version of the standard trust game with no initial endowment for the trustee, indicate an almost linear increase in trust levels in childhood and adolescence and a stable pattern for adults, with the exception of their retired participants whose trust level is significantly lower than those of their working professional group and their student group. More specifically, 8-year olds transfer only an average of $20 \%$ of their endowment to trustees, 12-year olds transfer 36\%, 16-year olds transfer 55\%, and the adult groups (excluding the group of retirees with $54 \%$ ) transfer more than $65 \%$.

Low levels of trust among the young participants in this study are rationalized by even lower levels of trustworthiness. The youngest age group, the 8-year olds, returns only $10 \%$ of whatever they have received. This rate increases to $15 \%$ for 12 -year olds and to more than $30 \%$ for 16 -year olds. It seems that the level of trustworthiness is quite stable from an age of around 15 to 16 years on, with return rates between $30 \%$ and $40 \%$ for all age groups aged 16 and older, with the notable exception of the group of retired participants who exhibit a spectacular return rate of 57\%.

If one wants to summarize the main findings in Sutter and Kocher (2007) in a nutshell, one would highlight three aspects: First, trust seems to increase with age in childhood and adolescence and to stay constant in adulthood. Second, trustworthiness or reciprocity seems to reach a certain average level (of around one third, which is notably exactly the threshold for making trust profitable for the trustor, on average, if the transfer is tripled) already at a younger age and then stays rather constant. Third, retired decision makers constitute an interesting exception with a lower level of trust than younger adults and a much higher level of trustworthiness, respectively reciprocity. Interestingly, the latter results seem in line with the evidence from panel surveys (see the previous section). ${ }^{5}$

Holm and Nystedt (2005) combine aspects of the experiment of Harbaugh et al. (2003b) and Sutter and Kocher (2007). They implement a mail-based trust game involving two groups of participants: 20-year old young adults and 70-year old retirees. The mail-based implementation requires the use of the strategy vector method for the return of the trustee. One interesting feature of the experiment is the option to provide a ranking of the preferred interaction partner for the game based on age and gender. More precisely, each trustor had to indicate a ranking of the four categories (women aged 20, men aged 20, women aged 70, and men aged 70) in terms of what category they

\footnotetext{
${ }^{5}$ Very similar results are provided by van den Bos et al. (2010), however, based on another variant of the trust game.
} 
wanted the trustee to come from. Matching was implemented in a way that ensured consideration of the ranking, and participants knew that.

In line with Sutter and Kocher (2007) younger participants trusted more, on average, than older participants in the study of Holm and Nystedt (2005). The difference is, however, not significant at conventional levels, which is probably a consequence of a comparatively small sample size. With regard to the preference over different interaction partners, the data show a clear in-group bias. Old decision makers tend to prefer old decisions makers, and young decision makers prefer young decision makers as interaction partners. Both have a preference for female trustees. The comparison of young and old trustees in terms of levels of trustworthiness is less conclusive. The slope of the strategy vector of return transfers of the group of old decision makers seems to be steeper than the slope of the 20year olds, i.e. they are more sensitive to the transfer levels chosen by trustors.

Table 1. (Laboratory) Experiments on the relationship between trust as well as trustworthiness and age

\begin{tabular}{|c|c|c|c|c|}
\hline & $\begin{array}{l}\text { Age span } \\
\text { covered }\end{array}$ & $\begin{array}{l}\text { Number of } \\
\text { participants }\end{array}$ & $\begin{array}{c}\text { Experimental } \\
\text { method }\end{array}$ & $\begin{array}{c}\text { Details of the } \\
\text { implemented trust game }\end{array}$ \\
\hline $\begin{array}{l}\text { Harbaugh et al. } \\
(2003 b)\end{array}$ & $\begin{array}{l}8 \text { to } 17 \text { years, } \\
\text { and adult group }\end{array}$ & 153 & Partly SVM & $\begin{array}{l}\text { Endowment: both } 4 \text { tokens } \\
\text { Multiplication: } \mathrm{x} 3 \\
\text { Reward: tokens into } \\
\text { presents }\end{array}$ \\
\hline $\begin{array}{l}\text { Holm and Nystedt } \\
(2005)\end{array}$ & $\begin{array}{l}20 \text { years and } 70 \\
\text { years }\end{array}$ & $\begin{array}{l}\text { 20-year olds: } 26 \\
\text { 70-year olds: } 55\end{array}$ & Partly SVM & $\begin{array}{l}\text { Endowment: both } 100 \\
\text { Swedish Kronor } \\
\text { Multiplication: } \mathrm{x} 3 \\
\text { Reward: money }\end{array}$ \\
\hline $\begin{array}{l}\text { Sutter and Kocher } \\
\text { (2007) }\end{array}$ & $\begin{array}{l}8 \text { to about } 80 \\
\text { years }\end{array}$ & $\begin{array}{l}\text { 8-year olds: } 90 \\
\text { 12-year olds: } 122 \\
\text { 16-year olds: } 100 \\
\text { Students: } 220 \\
\text { Professionals: } 62 \\
\text { Retirees: } 68\end{array}$ & Direct response & $\begin{array}{l}\text { Endowment: trustor } 10 \\
\text { tokens; trustee } 0 \text { tokens } \\
\text { Multiplication: } \mathrm{x} 3 \\
\text { Reward: money (control } \\
\text { treatments for different } \\
\text { stake sizes) }\end{array}$ \\
\hline Evans et al. (2013) & $\begin{array}{l}4 \text { to } 5 \text { years and } \\
9 \text { to } 10 \text { years }\end{array}$ & $\begin{array}{l}\text { 4/5-year olds: } 81 \\
\text { 9/10-year olds: } 91\end{array}$ & $\begin{array}{l}\text { Direct response; } \\
\text { no trustees } \\
\text { (deception) }\end{array}$ & $\begin{array}{l}\text { Endowment: } 1 \text { bag } \\
\text { Multiplication: } \mathrm{x} 4 \\
\text { Reward: bags with toys }\end{array}$ \\
\hline
\end{tabular}

Note: SVM = strategy vector method.

Evans et al. (2013) extend the research to younger children, with all the problems associated with explaining a trust game to a four-year old. They implement three games, of which one is a binary variant of the trust game. In particular, the experimenter show the participant in the role of the trustor a "surprise bag" containing toys such as pencils, key rings, stickers or balloons. Toys are wrapped and cannot be identified. The child can decide to keep the bag or send it to another child (in the role of the trustee) who would then receive four bags. The trustee can return two bags or none. Two other versions of the game (termed "altruism game" and "temptation game") are implemented to disentangle potential motives at different age levels. Participants were kindergarten children (aged 4 to 5 years) and primary school kids (aged 9 to 10 years). 
The main result of the study is that primary school children are much more trusting (79\%) than kindergarten children (27\%), even if the proper control for altruism (a "trust" game without the second stage, i.e. the trustee could not return any of the four bags that he or she might have received depending on the decision of the trustor) is applied at the individual level in a logistic regression.

Unfortunately, the experiment did not involve "real" trustees. The experimenters would come back to the children after a few days with two surprise bags and tell all children who had trusted that the trustee had returned two bags. Therefore, no decisions regarding trustworthiness could be recorded. Moreover, the time delay that was known to the children already when deciding could have had a stronger effect on kindergarten children than on primary school kids.

In a second experiment children were "interacting" with the other age group (i.e., kindergarten children also interacted with primary school kids and vice versa), and the delay for the feedback was removed. The original results were replicated, and, not very surprisingly, a greater sensitivity of older children with regard to the age of the interaction partner was observed.

\section{Mechanisms that "explain" trust and trustworthiness}

Can we "explain" the differences in trust and trustworthiness in different age groups? Since the most important developments seem to happen at young age, we mainly focus on evidence for children in the following.

Trust and trustworthiness are complicated social concepts, potentially relating to many motives or underlying preferences (e.g., Cox, 2004; Fehr, 2009). First and foremost, trust is a risky decisionthus, the alternative name "investment game" for the trust game (Eckel and Wilson, 2004). The risk is not a natural risk, but a social risk. While it is well-known that people might differ in their inclination to take natural risks on the one hand and social risks on the other hand (Bohnet and Zeckhauser, 2004), there are not enough studies that assess this difference, often termed "betrayal aversion" (capturing the observation that people seem to be more willing to take natural than social risks). In particular, there is no study that would look at the degree of betrayal aversion for different age levels in childhood and adolescence. Thus, we are left to look at natural risk attitudes when we want to address the risk component in trusting behavior for differently aged children. Sutter et al. (2013) do not find any significant change of natural risk attitudes, comparing ten-year olds and 16/17-year olds. A similar result holds for ambiguity attitudes that might be closer in nature to social risk because they imply unknown probabilities. Harbaugh et al. (2002) find evidence for a stronger degree of risk seeking behavior or less risk averse behavior among children than among adults. If relevant for the trust game, such behavior would imply more trust among kids than among adolescents, as opposed to the observed lower levels of trust. As a consequence, it is safe to rule out that potential changes in risk attitudes with age can explain the change in trusting behavior with age in childhood and adolescence. 
A much more promising line of explanation for the age differences in trust and trustworthiness is a potential change in pro-social attitudes when growing up. Psychologists have long been interested in studying the development of pro-social behavior in childhood and adolescence (e.g., Eisenberg et al., 1985; Eisenberg and Mussen, 1989; Eisenberg and Fabes, 1998). Unfortunately, most of these studies do not distinguish between different motives behind pro-social behavior and are thus not directly applicable to economic game situations or fall short of "explaining" particular changes. However, there is a growing literature in economics assessing certain kinds of pro-social motives among children and adolescents, trying to disentangle their influence.

The common finding of almost all studies on social behavior among kids is that pro-sociality becomes more prevalent the older children become. While the early results on bargaining behavior of children in versions of the ultimatum game in Murnighan and Saxon (1998) and the public goods game in Harbaugh and Krause (2002) are not fully conclusive when it comes to pro-social behavior and age, later papers mostly provide clear patterns. Harbaugh et al. (2003a) show that offers and transfers in ultimatum and dictator games increase with age, and Benenson et al. (2007) report similar developments for a dictator game and for children at a younger ageGummerum et al. (2010), using stickers in a dictator game (for a survey of bargaining experiments with children and adolescents, see Van Damme et al., 2014).

Angerer et al. (2015) provide evidence for a very large sample (more than 1000 children aged seven to eleven years) that also exhibits an increasing inclination with age to donate money to a real charity. Looking at different motivations, Fehr et al. (2008) show that, at an age of three to four years, children are mostly selfish, but when they grow older (seven to eight years), they become more inequity averse (for theoretical models of inequity aversion, see Fehr and Schmidt, 1999; Bolton and Ockenfels, 2000). Fehr et al. (2013) extend this result to older children. Almas et al. (2010) show that equity rather than equality norms are more important for older children. Martinsson et al. (2011) and Sutter et al. (2015) highlight the importance of social welfare concerns (i.e. efficiency concerns) that seem to constitute a more relevant aspect for social decision making, the older children are (for a theoretical model of efficiency concerns see, Charness and Rabin, 2002). ${ }^{6}$ Interestingly, many studies find gender differences in development and preferences (e.g., Cárdenas et al., 2014; Sutter et al., 2015). In the interest of space, we do not go into details here.

Taking the evidence on a development of different forms of pro-social behavior in childhood and adolescence together, a change in pro-sociality seems to be a good candidate explanation for the change in levels of trust and trustworthiness of children when growing older. It is beyond the scope of this paper to go into the details of the (ultimate) causes of such a development of pro-sociality and

\footnotetext{
${ }^{6}$ Dahlman et al. (2007) look at children aged three to eight years and analyze the extent of their reciprocal behavior (for theoretical models of reciprocity, see Dufwenberg and Kirchsteiger, 2004; Falk and Fischbacher, 2006). Results are consistent with what has been said so far. For evidence for even younger children, see for instance Warneken and Tomasello (2013).
} 
trust as well as trustworthiness with age. Obviously, emotional regulation (Crone et al., 2014) and cognitive abilities change with age. It is not surprising that the trust game has been used extensively to study emotions, in particular guilt and a potential aversion of humans toward guilt (Charness and Dufwenberg, 2006; Ellingsen et al., 2010). Genetic predispositions, neurological processes, and hormone correlates of behavior are all fascinating aspects when it comes to understanding the determinants of trust and their development with age. For the social scientist, trust experience at young age seems to be a relevant and much understudied determinant of individual differences in trusting behavior and trustworthiness at older age.

\section{Concluding remarks}

After all, we do not know nearly enough about the relationship between trust, trustworthiness and cooperation, on the one hand, and age, on the other hand. The development of trust and trustworthiness and cooperation in children is well-documented and well-understood, but how can it be explained? How can individual heterogeneity in trust and trustworthiness at the same age level be understood? The relative influence of genetic predispositions, proximate mechanisms such as emotions, and trust experience has not been researched a lot, and white spots in the literature are vast.

The development of trust and trustworthiness at old age is even more of a puzzle. The results from incentivized experiments and representative survey experiments, on the one hand, and questionnaire answers without marginal incentives, on the other hand, diverge, and no conclusive takehome message can be provided. Sociologists have been arguing that levels of trust are correlated with the number of interactions of an individual. This would imply that experience is shaping trusting behavior, but unfortunately, no study so far has been able to convincingly show whether this relationship is causal. Finding a good instrument seems to be a very valuable endeavor. However, even if we knew that there is a causal relationship between experience (and hence indirectly, age) and trust, it is still a long way to understand how exactly good and bad experience with (trust) relationships might shape the specifics of trusting and trustworthy behavior. For cooperation, Van Lange et al. (1997) provide results based on the elicitation of social value orientation. They show that childhood experience and patterns of social interaction shape cooperative attitudes of adults.

There is also a lack of methodological contributions. The literature has focused on comparing incentivized and non-incentivized measures of trust, i.e. game interaction and questionnaires, to address the issue of consistency (e.g., Glaeser et al., 2000; Gächter et al., 2004; Thöni et al., 2012). However, such studies have not been conducted for children, to the best of our knowledge. Incentives may work very differently for kids, adolescents, and adults. Large-scale validations of methods to elicit trust and trustworthiness are very scarce, again in particular for children and adolescents. While inter-cultural studies in trust based on survey questionnaires are abundant, there is much less inter- 
cultural evidence for the incentivized trust game, and almost no cross-cultural evidence for children and adolescents. Probably, knowledge of cultural differences in the development of trust and trustworthiness could help in getting a better grip on issues related to the potentially causal relationship between experience and trust. A related interest is on the effects of institutions (such as schools or the social environment) on trust and trustworthiness of individuals (e.g., Van Lange et al., 1997; Kocher et al., 2012), and again there is little conclusive evidence.

More work is needed to assess trust and trustworthiness in the direct interaction between different groups (e.g., Falk and Zehnder, 2013), in particular between different age groups. With children, the difference between trust within the family or the circle of close friends compared to trust toward strangers seems of special scholarly interest. The two levels appear to develop very differently, and pathological developments could potentially explain the existence of out-group hate or other severe problems in social interactions. Finally, trust within networks and the spread of trust in networks (i.e. peer effects of trust and trustworthiness) have barely been assessed.

Given the relevance of trust for understanding economic activity, but also for understanding dysfunctional aspects of societies such as discrimination or stereotypes (see, e.g., Fershtman and Gneezy, 2003), it is surprising how little we still know about its development, its roots and its determinants. While social psychologists and developmental psychologists naturally have a vested interest in the research questions associated with the development of trust and trustworthiness, there are also many links to economic models and many aspects relevant to economists. Understanding the development of trust and trustworthiness together with understanding their determinants ultimately means understanding growth, trade, and investment—concepts at the core of traditional economics. 


\section{References}

Alesina, A., La Ferrara, E. (2002), Who trusts others? Journal of Public Economics 85: 207-34.

Almas, I., Cappelen, A.W., Sorensen, E.O., Tungodden, B. (2010), Fairness and the development of inequality acceptance. Science 328: 1176-8.

Amir, O., Rand, D.G., Gal, Y.K. (2012), Economic games on the internet: The effect of $\$ 1$ stakes. PLoS ONE 7: e31461.

Angerer, S., Glätzle-Rützler, D., Lergetporer, P., Sutter, M. (2015), Donations, risk attitudes and time preferences: A study on altruism in primary school children. Journal of Economic Behavior and Organization, forthcoming.

Bargh, J.A., Chen, M., Burrows, L. (1996), Automaticity of social behavior: direct effects of trait construct and stereotype-activation on action. Journal of Personality and Social Psychology 71: 230-44.

Bellemare, C., Kröger, S. (2007), On representative social capital. European Economic Review 51: 183-202.

Benenson, J.F., Pascoe, J., Radmore, N. (2007), Children's altruistic behavior in the dictator game. Evolution and Human Behavior 28: 168-75.

Berg, J., Dickhaut, J., McCabe, K. (1995), Trust, reciprocity, and social history. Games and Economic Behavior 10: 121-42.

Bernath, M.S., Feshbach, N.D. (1995), Children's trust: Theory, assessment, development, and research directions. Applied and Preventive Psychology 4: 1-19.

Bohnet, I., Zeckhauser, R. (2004), Trust, risk and betrayal. Journal of Economic Behavior and Organization 55: 467-84.

Bolton, G.E., Ockenfels, A. (2000), ERC - A theory of equity, reciprocity and competition. American Economic Review 90: 166-93.

Camerer, C.F. (2003), Behavioral Game Theory. Experiments in Strategic Interaction. Princeton University Press.

Cárdenas, J-C., Dreber, A., von Essen, E., Ranehill, E. (2014), Gender and cooperation in children: Experiments in Colombia and Sweden. PLoS ONE 9: e90923.

Charness, G., Dufwenberg, M. (2006), Promises and partnership. Econometrica 74: 1579-601.

Charness, G., Rabin, M. (2002), Understanding social preferences with simple tests. Quarterly Journal of Economics 117: 817-69.

Coleman, J. (1990), Foundations of Social Theory. Belknap Press of Harvard University Press.

Cox, J.C. (2004), How to identify trust and reciprocity. Games and Economic Behavior 46: 260-81.

Crone, E.A., Will, G.-J., Overgaauw, S., Güroğlu, B. (2014). Social decision-making in childhood and adolescence. In: van Lange, P.A.M., Rockenbach, B., Yamagishi, T. (eds.). Reward and Punishment in Social Dilemmas. New York, Oxford University Press: 161-81. 
Dahlman, S., Ljungqvist, P., Johannesson, M. (2007), Reciprocity in young children. Working Paper, Stockholm School of Economics.

Doyen, S., Klein, O., Pichon, C.-L., Cleeremans, A. (2012), Behavioral priming: It's all in the mind, but whose mind? PLoS ONE 7: e29081.

Dufwenberg, M., Kirchsteiger, G. (2004), A theory of sequential reciprocity. Games and Economic Behavior 46: 268-98.

Eckel, C.C., Wilson, R.K. (2004), Is trust a risky decision? Journal of Economic Behavior and Organization 55: 447-65.

Eisenberg, N. Boehnke, K., Schuhler, P., Silbereisen, R.K. (1985), The development of prosocial behavior and cognitions in German children. Journal of Cross-Cultural Psychology 16: 69-82.

Eisenberg, N., Fabes, R. A. (1998), Prosocial development. In: Damon, W. (ed.), Handbook of Child Psychology. J. Wiley.

Eisenberg, N., Mussen, P. (1989), The Roots of Prosocial Behavior in Children. Cambridge University Press.

Ellingsen, T., Johannesson, M., Tjøtta, S., Torsvik, G. (2010), Testing guilt aversion. Games and Economic Behavior 68: 95-107.

Ermisch, J., Gambetta, D., Laurie, H., Siedler, T., Uhrig, N.S.C. (2009), Measuring people's trust. Journal of the Royal Statistical Society: Series A (Statistics in Society) 172: 749-69.

Evans, A.M, Athenstaedt, U, Krueger, J.I. (2013), The development of trust and altruism during childhood. Journal of Economic Psychology 36: 82-95.

Falk, A., Fischbacher, U. (2006), A theory of reciprocity. Games and Economic Behavior 54: 293-315.

Falk, A., Zehnder, C. (2013), A city-wide experiment on trust discrimination. Journal of Public Economics 100: 15-27.

Fehr, E. (2009), On the economics and biology of trust. Journal of the European Economic Association 7: 235-66.

Fehr, E., Bernhard, H., Rockenbach, B. (2008), Egalitarianism in young children. Nature 454: 107983.

Fehr, E., Glätzle-Rützler, D., Sutter, M. (2013), The development of egalitarianism, altruism, spite and parochialism in childhood and adolescence. European Economic Review 64: 369-83.

Fehr, E., Fischbacher, U., von Rosenbladt, B., Schupp, J., Wagner, G.G. (2003), A nationwide laboratory. Examining trust and trustworthiness by integrating behavioral experiments into representative surveys. Institute for Empirical Research in Economics. Working Paper 141. University of Zurich.

Fehr, E., Kirchsteiger, G., Riedl, A. (1993), Does fairness prevent market clearing? An experimental investigation. Quarterly Journal of Economics 108: 437-60.

Fehr, E., List, J.A. (2004), The hidden costs and returns of incentives - Trust and trustworthiness among CEOs. Journal of the European Economic Association 2: 743-71. 
Fehr, E., Schmidt, K. (1999), A theory of fairness, competition, and cooperation. Quarterly Journal of Economics 114: 817-68.

Fehr, E., Tougareva, E., Fischbacher, U. (2014), Do high stakes and competition undermine fair behaviour? Evidence from Russia. Journal of Economic Behavior and Organization 108: 35463.

Gächter, S., Herrmann, B., Thöni, C. (2004), Trust, voluntary cooperation, and socio-economic background: Survey and experimental evidence. Journal of Economic Behavior and Organization 55: 505-31.

Glaeser, E.L., Laibson, D., Scheinkman, J.A., Soutter, C.L. (2000), Measuring trust. Quarterly Journal of Economics 115: 811-46.

Guiso, L. Sapienza, P., Zingales, L. (2009), Cultural biases in economic exchange? Quarterly Journal of Economics 124: 1095-131.

Gummerum, M., Hanoch, Y., Keller, M., Parsons, K., Hummel, A. (2010), Preschoolers' allocations in the dictator game: the role of moral emotions. Journal of Economic Psychology 31: 25-34.

Harbaugh, W.T., Krause, K., Vesterlund, L. (2002), Risk attitudes of children and adults: Choices over small and large probability gains and losses. Experimental Economics 5: 53-84.

Harbaugh, W.T., Krause, K., Liday, S.G. Jr. (2003a), Bargaining by children. Working Paper, University of Oregon.

Harbaugh, W.T., Krause, K., Liday, S.G. Jr., Vesterlund, L. (2003b), Trust in children. In: Ostrom, E., Walker, J. (eds.), Trust, Reciprocity and Gains from Association: Interdisciplinary Lessons from Experimental Research. Russell Sage Foundation, New York.

Holm, H., Nystedt, P. (2005), Intra-generational trust - A semi-experimental study of trust among different generations. Journal of Economic Behavior and Organization 58: 403-19.

Johnson, N.D., Mislin, A.A. (2011), Trust games: A meta-analysis. Journal of Economic Psychology 32: 865-89.

Knack, S., Keefer, P. (1997), Does social capital have an economic payoff? Quarterly Journal of Economics 112: 1251-73.

Kocher, M.G., Martinsson, P., Visser, M. (2008), Does stake size matter for cooperation and punishment? Economics Letters 99: 508-11.

Kocher, M.G., Martinsson, P., Visser, M. (2012), Social environment, cooperative behavior and normenforcement. Journal of Economic Behavior and Organization 81: 341-54.

LaPorta, R., Lopez-de-Silane, F., Shleifer, A., Vishny, R.W. (1997), Trust in large organizations. American Economic Review 87: 333-8.

Ledyard, J. (1995), Public goods. A survey of experimental research. In: Roth, A., Kagel, J. (eds.), Handbook of Experimental Economics. Princeton University Press, Princeton: 111-93.

Li, T., Fung, H.H. (2013), Age differences in trust: An investigation across 38 countries. Journals of Gerontology Series B: Psychological Sciences and Social Sciences 68: 347-55. 
Martinsson, P., Nordblom, K., Rützler, D., Sutter, M. (2011), Social preferences during childhood and the role of gender and age - An experiment in Austria and Sweden. Economics Letters 110: $248-51$.

Murnighan, J.K., Saxon, M.S. (1998), Ultimatum bargaining by children and adults. Journal of Economic Psychology 19: 415-45.

Naef, M., Fehr, E., Fischbacher, U., Schupp, J., Wagner, G. (2008), Decomposing trust: Explaining national and ethnic trust differences. Working Paper, Institute for Empirical Research in Economics, University of Zurich.

Poulin, M.J., Haase, C.M. (2015), Growing to trust: Evidence that trust increases and sustains wellbeing across the life span. Social Psychological and Personality Science, forthcoming.

Poundstone, William (1992), Prisoner's Dilemma. Doubleday, New York.

Putnam, R. (2000), Bowling Alone: The Collapse and Revival of the American Community. Simon and Schuster, New York.

Rousseau, D.M., Sitkin, S.B., Burt, R.S., Camerer, C. (1998), Not so different after all: A crossdiscipline view of trust. Academy of Management Review 23: 393-404.

Sutter, M., Feri, F., Glätzle-Rützler, D., Kocher, M.G., Martinsson, P., Nordblom, K. (2015), Social preferences in childhood and adolescence. A large-scale experiment. Working Paper, University of Innsbruck

Sutter, M., Kocher, M.G. (2007), Trust and trustworthiness across different age groups. Games and Economic Behavior 59: 364-82.

Sutter, M., Kocher, M.G., Glätzle-Rützler, D., Trautmann, S.T. (2013), Impatience and uncertainty: Experimental decisions predict adolescents' field behavior. American Economic Review 103: 510-31.

Thöni, C., Tyran, J.-R., Wengström, E. (2012), Microfoundations of social capital. Journal of Public Economics 96: 635-43.

Van Damme, E., Binmore, K., Roth, A. et al. (2014), How Werner Güth's ultimatum game shaped our understanding of social behavior. Journal of Economic Behavior and Organization 108: 292318.

Van den Bos, W., Westenberg, M., van Dijk, E., Crone, E.A. (2010), Development of trust and reciprocity in adolescence. Cognitive Development 25: 90-102.

Van Lange, P.A.M, Otten, W., De Bruin, E.M.N., Joireman, J.A. (1997), Development of prosocial, individualistic, and competitive orientations. Theory and preliminary evidence. Journal of Personality and Social Psychology 73: 733-46.

Warneken, F., Tomasello, M. (2013), The emergence of contingent reciprocity in young children. Journal of Experimental Child Psychology 116: 338-50.

Zak, P.J., Knack, S. (2001), Trust and growth. Economic Journal 111: 295-321. 